\title{
Agricultura Tradicional en la Nueva España
}

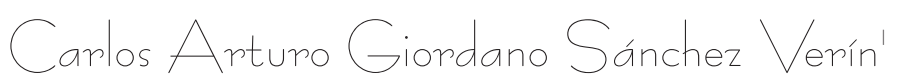

Cuando hablo de agricultura tradicional me quiero referir a los sistemas de uso de la tierra que se han desarrollado de manera local durante muchos años de experiencia empírica y de experimentación campesina o indígena. Existen muchas definiciones de este concepto, sin embargo debemos decir que la agricultura tradicional ha sido estudiada principalmente por los antropólogos, partiendo, en muchos de los casos, de que la introducción de técnicas occidentales recientes han resultado, a lo largo del tiempo, un fracaso por no haberse adaptado a las condiciones ecológicas y culturales, que es precisamente en donde se desarrolla.

Podemos decir que la llamada Agricultura Tradicional en México, nombrada por Ángel Palerm "Agricultura Mexicana", es producto de los sistemas y técnicas agrícolas que se emplearon fundamentalmente en el siglo xvi en la Nueva España. Entre sus principales características se encuentran en atraso técnico y tecnológico que implican una economía de subsistencia y se dedica primordialmente al gasto familiar gran parte de lo cosechado. Sabemos que este tipo de agricultura lo practican en la actualidad alrededor de $1 / 5$ de la población indígena y campesina del mundo, a pesar de que se han hecho importantes intentos por modificar esta situación.

\footnotetext{
${ }^{1}$ Doctor en Historia por la Universidad Nacional Autónoma de México. Profesor de la Universidad Iberoamericana Golfo-Centro y Seminario de Cultura Mexicana. giord_gom@hotmail.com 
En el caso de la Nueva España, ${ }^{2}$ fue el propio Hernán Cortés quien trajo en 1524 a estas tierras las primeras herramientas agrícolas que se usaron para la siembra y corte de la caña de azúcar, y hacia 1530, a su regreso de España trajo hierro, acero y unos azadones y azaderas que "compraron los viñeros y costaron siete ducados"

De esta manera, podemos decir que con la llegada de los conquistadores españoles también llegaron una gran cantidad de instrumentos de labranza, animales y materiales nuevos que ayudaron y favorecieron a la agricultura nativa.

En este sentido es importante señalar que el siglo xvi fue un periodo de tiempo para aprender cómo hacer cosas; ocurrieron cambios en la agricultura indígena prehispánica y éstos no fueron ni fáciles ni rápidos como a veces lo suponemos. ${ }^{4}$ Los suelos y los cambios climatológicos fueron de gran importancia para las comunidades indígenas debido a que su economía dependía de manera fundamental del abasto de agua y de tierras adecuadas para el cultivo, ya que su principal actividad siguió basada en la agricultura y, dentro de ella, el maíz continuó siendo el más importante cultivo, seguido por el frijol (Phaseolus), el chile (Capiscum) y el maguey (Agave) $^{5}$. Sin embargo, con el tiempo éstos redujeron la extensión de sus tierras cultivadas debido al acaparamiento de ellas por parte de los españoles.

Con la introducción de nuevas especies, de sistemas y técnicas agrícolas y, por supuesto, de una nueva forma de tenencia de la tierra, se inició una revolución en la agricultura

${ }^{2}$ Sabemos que el nombre de Nueva España lo debemos al conquistador Hernán Cortés, quien cuando escribió su Segunda Carta de Relación al emperador Carlos V, sugirió el nombre por, según él, tratarse de un territorio similar al de España.

${ }^{3}$ MARTÍNEZ, J.L., Documentos cortesianos, México: Fondo de Cultura Económica, 1991, t. III. , pp. 116-126.

4 JÁCOME, Alba González, "The ecological basis of the indigenous nahua agriculture in the sixteenth century", en Agriculture and human values, Kluwer Academic Publishers B. V., 2004, pp. 117-127, p. 117.

${ }^{5}$ Se incorporan los nombres científicos de las plantas, sin embargo, debido a que en la mayoría de los casos se tratan de muchas variedades de la misma planta, sólo se especifica el que hace referencia al nombre genérico. Lo mismo se hace con las subsecuentes referencias de plantas y árboles. 
mesoamericana, que no fue aplicada y empleada por todas las poblaciones indígenas, por lo menos en las primeras décadas posteriores a la conquista. Prueba de ello es que hasta la fecha se continúan utilizando en muchas regiones del país las mismas técnicas y sistemas prehispánicos que se han usado desde, al menos, principios del siglo xvi.

Sabemos que los conquistadores y los migrantes europeos se preocuparon por obtener grandes extensiones de tierras, aún en aquéllos sitios donde les estaba prohibido establecerse, como la Provincia de Tlaxcala, donde para el primer tercio del siglo xvi ya había más de 130 haciendas y un gran número de ranchos. La iglesia, por su parte, también participó de manera activa en este proceso y muy pronto se convirtió en la mayor propietaria de tierra en la Nueva España.

De esta manera, ya para el siglo xvi, se podían observar por todo el territorio novohispano grandes haciendas que explotaban la tierra para obtener diversos productos agricolas y pecuarios que abastecian de manera importante a los mercados locales y regionales, mientras que la agricultura indigena, acostumbrada a producir lo básico para su alimentar a los miembros de la comunidad, comerciar o intercambiar productos y pagar tributos, quedó condenada a una agricultura que no pudo competir con la de las haciendas y ranchos .

Desde entonces, el paisaje ha cambiado de forma considerable. En muchas regiones la cubierta vegetal se ha destruido por el desmonte y el pastoreo, así como una explotación intensiva de la tierra, lo que ha provocado una fuerte erosión. Sin embargo, a principios del siglo xvii, se contaba con exuberante y variada vegetación de acuerdo a las condiciones edáficas específicas. Existían en abundancia pinos (Pinus), encinos (Quercus Laurina), robles (Quercus robur L.), álamos (Populus), Oyameles (Abies religiosa) cedros (Cedrus Spp.), cipreses (Cupressus sempervirens L.), abetos (Abies alba Mill), sauces (Salix Bonplandia) madroños (Arbutus unedo), yuccas (Manihot esculenta), pirules (Schinus Molle) y eucaliptos (Eucalyptus) entre otros. 


\section{Agricultura indigena:}

Para el desarrollo de la actividad agrícola, destinada principalmente al autoconsumo y al pago de tributos, los indigenas continuaron empleando el sistema agrícola tradicional basado en el maíz, cuya herramienta principal era la coa o bastón plantador. ${ }^{6}$ Sobre esto nos dice Gibson que "Una agricultura indígena muy sencilla, con pocas cosechas y con el equipo más escaso compuso la economía de subsistencia para el grueso de la población india a lo largo del siglo xvi." Esta es una afirmación con la que no estamos de acuerdo, ya que si bien no contaban con herramientas sofisticadas, si contaban con un gran conocimiento sobre el entorno, hecho que les permitió obtener excedentes que sirvieron para comerciar o intercambiar por otros productos. En algunos casos los indios principales fueron incorporando poco a poco el arado y los bueyes, con la intención de obtener mayores cosechas y realizar menos trabajo. Nos dice Trautmann ${ }^{8}$ que se empleaban principalmente tres sistemas agrícolas, dos de ellos con regadio:

- Cultivo de temporal. Este sistema ha sido el más importante y se fundamenta en el periodo de lluvias estivales y estaba regido por el inicio y la duración de las precipitaciones. "...la siembra del maíz se llevaba a cabo, según datos documentales, en mayo y se cosechaba en septiembre."

- Cultivo de humedad o por inundación. Las regiones con suelos húmedos o con altos niveles freáticos son las que permiten este tipo de cultivo. En algunos documentos

\footnotetext{
${ }^{6}$ Para conocer con mayor detalle la descripción de los instrumentos e implementos agrícolas, se recomienda consultar a ROJAS Rabiela, Teresa, Las siembras de ayer. La agricultura indigena del siglo XVI, México, SEP/CIESAS, 1988. pp. 155-174.

7 GIBSON, Charles, Tlaxcala en el siglo xvi, trad. de Agustín Bárcena, México: Gobierno del Estado de Tlaxcala/Fondo de Cultura Económica, 1991. , p. 146.

8 TRAUTMANN, Wolfgang, Las transformaciones culturales en el paisaje de Tlaxcala durante la época colonial. Una contribución a la historia de México bajo especial consideración de aspectos geográficos-económicos y sociales. Wiesbaden: Franz Steiner Verlag GMBH, 1981, p. 53.
} 
se le conoce a este sistema como de "camellones", aunque puede referirse también al cultivo en vegas rivereñas, o a cultivos en zonas inundables. ${ }^{9}$

- Cultivo de riego. Es poca la información que existe al respecto, sin embargo sabemos que las regiones que contaban con ríos cercanos aprovechaban esa agua para regar sus plantaciones, así como las chinampas que existieron en el Altiplano Central. En algunas regiones se emplearon los antiguos sistemas hidráulicos de la agricultura intensiva precortesiana que se caracterizaba por aprovechar la humedad existente en riveras, embalses, vegas de los ríos y lagunas y sistemas de riego donde fluía el agua de manera continua.

Los más importantes de estos sistemas agrícolas fueron el de temporal, porque constituyó la verdadera expansión de la agricultura, y los sistemas de terrazas, metepantles o bancales que tienen hasta la actualidad la finalidad de captar y retener el agua, así como materiales en descomposición que sirven de abono. ${ }^{10}$

El cultivo del maíz respondía a un ciclo anual y con un periodo de madurez de alrededor de seis meses, aunque esto dependía de las regiones en que se sembrara, ya que por lo general se iniciaba esta actividad en el mes de marzo o abril, en cuanto empezaban las lluvias, aunque en algunas partes se podía prolongar hasta el mes de mayo, ${ }^{11}$ buscando evitar las heladas que tanto daño hacían a las plantas, ya que una sola de ellas podía acabar de manera casi inmediata con toda la cosecha.

La planta del maíz se puede sembrar en casi cualquier tipo de suelo, desde los arenosos hasta los muy rocosos. Su raíz poco profunda no requiere de gran preparación del terreno ni de fertilizantes, además de que soporta altas tempera-

\footnotetext{
9 JÁCOME, Alba González, comunicación personal, 1998.

${ }^{10}$ Sobre este tema es importante leer la abundante obra de Alba González Jácome.

${ }^{11}$ Sabemos que la estación de lluvias se registraba en el verano, entre los meses de abril-mayo y duraban hasta agosto-septiembre. 
turas ya que es capaz de conservar la humedad por periodos prologados. Sin embargo, su cultivo resulta ser de una gran incertidumbre si se expone a cambios drásticos de temperatura. Así, "Sus malos años eran de depresión para la sociedad indígena, y sus años buenos eran de prosperidad". ${ }^{12}$ La información obtenida no permite determinar si el periodo invernal, que es seco y que sigue a la cosecha, constituía el único descanso para la tierra, o si existía una rotación que incluía pausas más prolongadas. ${ }^{13}$

Las variedades y colores en las semillas de maíz variaban de una región a otra debido a las diferencias de suelos, climas y, por supuesto, del uso que hacían. Gibson ${ }^{14}$ nos dice que las semillas que se cosechaban en la región de Toluca eran preciadas por su calidad, además de que podían conservarse por mucho tiempo, a diferencia de las que se obtenían en Tlaxcala, que tenían fama de deteriorarse rápidamente, a pesar de que "sin duda ninguna es la más fértil provincia y abundosa de maíz y otros mantenimientos y legumbres que hay en toda esta Nueva España...". ${ }^{15}$

Por lo general, las familias indias que habitaban en zonas anegadizas y cultivaban maíz, en la etapa de deshierbe hacían montoncitos de tierra, llamados "mogotes", ${ }^{16}$ arreglados en hileras, tal y como se aprecia en una ilustración de fray Bernardino de Sahagún que se localiza en el Códice Florentino. ${ }^{17}$ Sabemos que se depositaban entre tres y seis semillas por montón y que éstos se hacían aproximadamente a un metro de distancia uno de otro.

\footnotetext{
${ }_{12}$ GIBSON, Charles. Los aztecas bajo el dominio español (1519-1810). México: Siglo XXI, 1981, p. 314.

${ }^{13}$ PASO Y TRONCOSO, Francisco del, Epistolario de la Nueva España, 1505-1818, México: 1940, 16 v., t. XV, p. 61.

${ }^{14}$ GIBSON, Charles. Los aztecas..., p. 314.

15 CAMARGO, Diego Muñoz, Relaciones geográficas del siglo xvi, México: edición de René Acuña, Universidad Nacional Autónoma de México, 1984, 2 t., t. I, p. 36

${ }^{16}$ Hasta la fecha a esta actividad se le llama "amogotar" o "aterrar".

${ }^{17}$ Códice Florentino, México, Archivo General de la Nación, 1981., libro vi, p. 9.6
} 
De acuerdo con una estimación hecha por Arij Oweneel, ${ }^{18}$ una familia cuyo promedio era de cuatro o cinco integrantes requería alrededor de 25 fanegas de maíz por año, lo que equivale a más de dos fanegas al mes. Si tomamos en cuenta que una fanega de maíz equivale aproximadamente a $46 \mathrm{Kgs}$., significa que cada familia consumía un promedio de $1150 \mathrm{Kgs}$. de maíz al año y alrededor de $95 \mathrm{Kg}$. cada mes.

Conocemos por la investigación realizada por Arístides Medina Rubio, sobre los diezmos del Obispado de Puebla que entre 1602 y 1624, que el precio del maíz tlaxcalteca fluctuó entre 5 y 20 reales la fanega, y que durante estos mismos años se registró un incremento en la producción de este grano en Tepeyanco, Nativitas, Ixtacuixtla, Apizaco y Huamantla. ${ }^{19}$ Con base en los documentos de archivo consultados sabemos que para 1728 el precio del maíz fluctuó entre 8 y 12 reales por fanega. ${ }^{20}$

En las haciendas tlaxcaltecas a principios del siglo xviii la siembra del maíz se hizo en condiciones diferentes a las que tradicionalmente se habian hecho, ya que

Sembrar en mayo era ya demasiado tarde. La maduración de la planta era estimulada por tres o cuatro labores, escardas $\mathrm{y}$, si era necesario, por un riego. Después de la última labor, normalmente la aterradura o aporque, ${ }^{21}$ comenzaba la vigilancia de la milpa por el milpero, es decir, entre finales de julio y principios de enero. La cosecha tenía lugar hacia la entrada del año nuevo. ${ }^{22}$

\footnotetext{
${ }^{18}$ OWENEEL, Arij, Shadows over Anahuac. An ecological interpretation of crisis and development in Central Mexico, 1730-1800, Albuquerque, University of New Mexico Press, 1996., p. 6.

${ }_{19}$ URQUIOLA, José, "Empresarios y obrajeros primitivos: el obraje textil en el siglo xvi en la Nueva España", México, tesis de maestría en antropología social, Universidad Iberoamericana, 1987, p. 62.

${ }^{20}$ Archivo General de la Nación (AGN), Tierras, Vol. 1443, exp. 3.

${ }^{21}$ Arrimar tierra a la base del tallo o tronco de las plantas. Es lo mismo que "amogotar".

${ }^{22}$ OWENEEL, Arij, "Don Claudio Pesero y la administración de la hacienda de Xaltipan (1734-1737). Historia y sociedad en Tlaxcala. Memorias del $2^{\circ}$ Simposio Internacional de Investigaciones Socio-Históricas sobre Tlaxcala, 15 al 17 de octubre de 1986, Tlaxcala: Gobierno del Estado de Tlaxcala/ Instituto Tlaxcalteca de la Cultura, Universidad Autónoma de Tlaxcala/ Universidad Iberoamericana, Tlaxcala, 1989, pp. 57-71., p. 68. 
La manera de consumir el maíz fue la misma que desde hacía varios siglos se practicaba. La más común era en forma de tortillas que preparaban las mujeres de las familias indigenas. Para su elaboración, al igual que hasta la fecha, se remojaban las semillas en agua de cal y después se molían con el metate y se cocían en un comal. En varias zonas del centro de México en lugar de cal se empleaba el tequesquite. Asimismo, se hacía, como hasta la fecha, una bebida llamada atole con granos de maíz remojados y cocidos en agua, ${ }^{23}$ mientras que las hojas y los tallos de la planta se emplearon desde el periodo virreinal como forraje para los animales, en especial para los puercos, caballos y mulas, además de utilizarse como material de construcción.

El maíz, una vez cosechado, se almacenaba con la intención de contar con él mientras llegaba la siguiente cosecha. Para ello se emplearon desde ollas de barro hasta trojes que podían variar su tamaño si eran familiares o las que se construyeron en las haciendas y que pudieron contener grandes cantidades de grano.

Es importante mencionar que un sistema agrícola de suma importancia lo constituyeron las chinampas, sin embargo éstas no se pudieron construir en todas partes, pues requerian de condiciones específicas en tierras inundables, lagunas o lagos. Sabemos que la producción que se obtenía de ellas era mucho mayor que la que se alcanzaba en otras tierras. Una hectárea de chinampa cosechada equivalía a cuatro hectáreas de riego; a 11 hectáreas de temporal y a 40 hectáreas de roza.

Sobre las trojes, nos dice Hernández Xolocotzi ${ }^{24}$ que "los graneros tribales y los familiares representaban una cuenta de ahorros que mantenía el desastre a distancia y sostenía el vigor social". Sin embargo, y a pesar de ser la planta más popular entre los indigenas, ésta debía contar con cuidados especiales durante su almacenamiento, ya que los granos

${ }^{23}$ Cuando se condimenta con chile se le llama chileatole.

${ }^{24}$ XOLOCOTZI, Efraím Hernández, "Graneros de maíz en México", en Xolocotzia. Obras de Efrain Hernández Xolocotzi, México: Universidad Autónoma de Chapingo, 1985, pp. 205-230., p. 205. 
son susceptibles a plagas y enfermedades que llegan a destruirlos. Entre los graneros prehispánicos más conocidos se encuentran los cuezcomates que son vasiformes hechos de zacate y arcilla.

Es importante mencionar que los cultivos indígenas tuvieron, por lo menos durante la época prehispánica y buena parte del siglo xvi, una finalidad casi totalmente de autoconsumo. Gibson ${ }^{25}$ señala que la producción comercial de maíz se ha señalado entre 1580 y 1630, fecha en que las haciendas productoras de este grano ya tenian todas las ventajas productivas sobre las comunidades indias: contaban con grandes extensiones de tierra e importantes formas de almacenamiento y transporte, además de que controlaban la mano de obra indigena y hasta podian controlar los precios del producto en los mercados regionales.

Por su parte, el chile, otro de los cultivos de gran importancia entre las comunidades indias del centro de México, requiere de mayor humedad que el maíz, por lo que es posible que se haya sembrado principalmente en las llanuras localizadas entre los ríos o cercanos a las lagunas, ya que éstas poseen un alto nivel freático a lo la largo de todo el año. De acuerdo con las Actas del Cabildo de Tlaxcala, este producto se sembraba en las orillas de las "tierras húmedas" y ahí mismo se transplantaba el chile de estío (tonalchilli). ${ }^{26}$

Sin duda incluían en estos mismos terrenos calabaza (Cucurbita pepo L.), cía (Salvia) y huauhtli (Amaranthus) ${ }^{27}$ bajo la agrupación de "yerbas y legumbres". Sabemos que algunos de estos productos se exportaban hacia las provincias vecinas, por lo menos durante el siglo xvi. ${ }^{28}$

La venta pública de productos no se permitía, ya que era común que se detectaran fraudes, contrabando y ventas

\footnotetext{
${ }^{25}$ GIBSON, Charles, Los aztecas..., p. 334.

${ }^{26}$ Citado por JÁCOME, Alba González, El ambiente y la agricultura en Tlaxcala durante el siglo xvi, mecanoescrito.

${ }^{27} \mathrm{El}$ amaranto puede ser blanco o negro y hasta la fecha la región de Tlaxcala que mayor producción tiene de esta planta es San Miguel del Milagro, cercano a la zona arqueológica de Cacaxtla.

28 Archivo del Ayuntamiento de Tlaxcala, ¿1587?, documentos sueltos. 
ilegales como sucedió durante el siglo xvi y xvii con la grana. Con la intención de evitar este tipo de problemas se aplicaron ciertas medidas de control, especialmente a la venta de maíz, trigo, lana, grana, carne y cacao. ${ }^{29}$

El maguey, que es una planta perenne que tarda en madurar hasta diez años, resultó de gran importancia para la economía indigena. De las 200 especies de maguey que se conocen en México, el Agave atrovirens, que es una de las más robustas de su género, fue la más empleada durante la época virreinal. Como lo mencionamos, tuvo una gran importancia entre la población indígena, ya que además de constituir un fundamento económico, tenía la enorme ventaja de crecer en los sitios más inhóspitos y extremos, y ofrecía una gran variedad de usos, incluyendo los agrícolas, a tal grado que Motolinía $^{30}$ nos dice que de él se hacen tantas cosas que se puede comparar con el hierro.

Quizá el producto más conocido en la actualidad es el pulque, que se obtiene haciendo un hoyo en el corazón de la planta, de donde mana el aguamiel, el cual es fermentado para obtener dicha bebida; así como miel, vinagre y azúcar. ${ }^{31}$

Por desgracia, el consumo de esta bebida rápidamente se difundió entre la población indígena sin mayor control, por lo que las autoridades intentaron limitar su consumo. En 1548 se multaba con medio tomin a quien se encontrara borracho y con un tomín a quien fermentara pulque.

Con toda seguridad las autoridades continuaron legislando en torno a este severo problema de la sociedad indígena novohispana. Cabe destacar que este es uno de los elementos que nos permite entender cómo se fragmentó la cultura

${ }^{29}$ AGN, Indios, VI, Primera Parte, núm. 335, fol. 90; Segunda Parte, núm. 722, fols. 168 - 168 v.). Entre las medidas se encontraba el designar "cuidadores" o "vigilantes" que inspeccionaban los centros de acopio y venta de estos productos.

${ }^{30}$ MOTOLINÍA, apud BENAVENTE, Fray Toribio de, Historia de los indios de la Nueva España, México: Porrúa, 1984, p. 197.

${ }^{31}$ VERÍN, Carlos Arturo Giordano Sánchez, Sistemas y técnicas tradicionales de la agricultura en Tlaxcala, mecanoescrito..., p. 45. 
y la cosmovisión nativa, ya que el pulque, de ser una bebida que se consumía casi de manera exclusiva en las ceremonias rituales, se transformó para ser usada de forma cotidiana y sin ninguna restricción, debido a que el maguey se cultivaba a nivel familiar.

Los castigos no debieron surtir los efectos deseados por las autoridades, ya que es común encontrar que, por ejemplo, a principios del siglo xvii en las visitas que hacían los jueces de obrajes a los talleres en los que se realizaban telas, se menciona que cuando los indios se presentaban a declarar muchas veces lo hacian borrachos y, por lo menos, en los documentos consultados en el Archivo General de Tlaxcala, no se menciona ningún tipo de sanción para ellos. ${ }^{32}$

Las Reales Cédulas de 1529, 1545, 1607 y la Ordenanza sobre el pulque de $1608^{33}$ prohibian el pulque, pero tan sólo aquél que no fuera blanco, así como otros ingredientes en su elaboración, ya que, como lo menciona Francisco Hernández, ${ }^{34}$ agregándole otras cosas embriaga más. Al respecto sabemos que, en efecto, era costumbre de acuerdo a cada región y con el propósito de acelerar el proceso de fermentación, agregar al aguamiel distintos tipos de hierbas y raices.

Una de las sustancias de origen claramente prehispánico que se añadian al pulque era el cuapatle (corteza de la Acacia angustissima); aunque la Corona había prohibido su uso en 1529 , se le menciona como un aditivo ordinario en diversas Relaciones Geográficas en el centro de México y Oaxaca. Motolinía habla del cuapatle u ocpatli como la "medicina" o "curación" producida por la fermentación del pulque. En otras fuentes del siglo xvi se habla con mayor precisión de que la corteza "da fuerza" al pulque y no de que cause su fermentación. Henry Bruman, que estudió las zonas

\footnotetext{
${ }^{32}$ VERÍN, Carlos Arturo Giordano Sánchez, Obrajes y economía en Tlaxcala a principios del siglo XVII. 1600-1630, México: Archivo General de la Nación, 2002. pp. 105-106.

${ }^{33}$ AGN, Indios, Vol. 17 Exp. 1, folio IV y Ordenanzas, t. ii, fs. 212-215v. El edicto de Luis de Velasco hijo contra el uso inmoderado del pulque, de 16 de agosto de 1608 , estaba apoyado en sus observaciones acerca de la embriaguez en la ciudad de México,

${ }^{34}$ HERNÁNDEZ, Francisco, Obras completas, México: UNAM, 1959, t. II., p. 349.

118 Revista de História Regional 15(1): 108-130, Verão, 2010
} 
prehispánicas de embriaguez en México, ha identificado el cuapatle como fuente de digitoxina, estimulante del corazón, lo que indudablemente determinaría que fuera más enérgico el efecto de la droga en la bebida. ${ }^{35}$

Los indios fueron los principales productores de pulque a lo largo de los siglos xvi y xvii, y existen numerosas peticiones hechas por los productores individuales para poder venderlo en las principales ciudades del valle de México. Las solicitudes se iniciaron a fines de los 1580 cuando se exigió a los virreyes y a las audiencias mayor control sobre el comercio de las bebidas alcohólicas. Las autorizaciones se otorgaban de manera casi inmediata, hasta que ocurrió la revuelta de la ciudad de México y de la de Tlaxcala en el año 1692, en la que la población indígena de ambas ciudades protestó al grado de quemar edificios de gobierno. ${ }^{36}$

Un paso importante en el proceso de la comercialización del pulque la dio Luis de Velasco con su Ordenanza de 1608 , ya que estableció las normas precisas que regirían la producción y su consumo. Esto implica que el comercio de la bebida era ya importante y contaba con una economía oficialmente reconocida. Un aspecto sobresaliente es que su producción se limita al sector indígena y excluía a cualquier otro grupo étnico "bajo graves penas". ${ }^{37}$ Se especifica en la Ordenanza que las pulquerías y la venta de pulque, así como todo lo que tenía que ver con esta bebida, debian estar en manos indígenas, los que se obligaban a sujetarse a ciertas normas.

Esta Ordenanza tuvo vigencia hasta el año 1648 debido a que en muchos casos ya no se ajustaba a la realidad. El pulque, y en especial su venta, dejó de ser algo exclusivo

\footnotetext{
35 TAYLOR, William, Embriaguez, homicidio y rebelión en las poblaciones coloniales mexicanas, México: Fondo de Cultura Económica, 1987. p. 53.

${ }^{36}$ AGN, Reales Cédulas, V. 25, E. 75, f. 3, diciembre 14 de 1693. En la ciudad de Tlaxcala los indios quemaron las "Casas Reales", que era el principal edificio de gobierno. Varios meses después el gobierno virreinal solicitó que se averiguara cuándo fue y los motivos que existieron.

${ }^{37}$ AGN, Ordenanzas, T. ii, fs. 212-215 v. Ordenanzas sobre el pulque de Luis de Velasco, México, agosto 16 de 1608.
} 
del sector indio por la intromisión de otros grupos étnicos, y en esto incidió, sin duda, el lucrativo amparo que numerosos alguaciles daban a las pulquerias, hechos que fueron denunciados y prohibidos por el virrey Alburquerque. ${ }^{38}$

No sabemos con exactitud dónde y cuándo se empezó a cobrar un impuesto por el pulque, ya que oficialmente nunca se ordenó ni se permitió tal medida en el territorio novohispano $\mathrm{y}$ todo parece indicar que fueron los alcaldes mayores de los pueblos circunvecinos a la ciudad de México quienes iniciaron la práctica. Sin embargo, y ante la situación fraudulenta que se originó, la Corona manifestó su desacuerdo, y en la primera resolución respecto al asiento de pulques en 1668 ordenó que todo lo que importase el impuesto y las licencias de pulquerias se enviase a la península de manera separada. Asimismo pidió a los oidores, virrey y Tribunal de Cuentas que le informaran sobre la conveniencia de la creación de esta nueva renta, así como los perjuicios que se podrian acarrear a los indígenas y los daños que se ocasionaría a la importación de vinos españoles.

Existieron muchos pros y contras al respecto. Uno de los pros que más motivaron a la Corona fue el cálculo que se hizo del ingreso anual para la ciudad de México por este concepto. Tanto los oficiales de Hacienda como el oidor Montemayor de Cuenca argumentaron que los ingresos anuales serian de 44 800 pesos, más 30 pesos al año por cada una de las 100 o 150 licencias que se deberían de dar. Por su parte el conde de Albade Liste y el duque de Alburquerque, quienes habían sido virreyes, se opusieron a este proyecto "puesto que los indios están libres de pagar impuestos sobre los frutos de sus tierras". ${ }^{39}$ Además el intenso comercio pulquero en la ciudad de México y otras ciudades importantes daría la oportunidad de que los alcaldes mayores cometieran nuevos abusos.

Debido a lo anterior fue que en ese año de 1668 se decidió nombrar a un administrador para que recaudara

\footnotetext{
${ }^{38}$ GUIJO, Gregorio M. de, Diario. 1648-1664, México: Porrúa, 1952, 2 t., p. 8

${ }^{39}$ PALOMO, José Jesús Hernández. La renta del pulque en Nueva España 16631810, Sevilla: Escuela de Estudios Hispano-Americanos de Sevilla, 1979., pp. 41-42.
}

120 Revista de História Regional 15(1): 108-130, Verão, 2010 
el impuesto en cada una de las tres jurisdicciones. De esta manera León Dalza lo hizo en México; Bartolomé de Mora y Espinoza en Puebla, Cholula y Tlaxcala, mientras que Bartolomé Ruiz lo hizo en Oaxaca. ${ }^{40}$

Vemos así que un factor muy importante para que las autoridades virreinales permitieran y alentaran el comercio de este tipo de bebidas fueron los impuestos que se recababan por ellas. En 1629 muchas poblaciones del centro de México afirmaban que dependian de la venta del pulque para poder vivir, ${ }^{41}$ por lo que vemos que desde el siglo xvi se establecieron mesones y pulquerias a orillas de los principales caminos con la intención de atender a los viajeros. ${ }^{42}$

El cultivo del maguey, que se seguía haciendo a la usanza prehispánica, tenía también la ventaja de que requería de poco cuidado, además de que con su siembra se controlaba la erosión de los suelos, ya que evitaba que los nutrientes fueran arrastrados por las lluvias en terrenos con pendiente. Hasta la fecha se sigue empleando esta técnica y suele hacerse una zanja de poca profundidad a un lado de los ahora llamados metepantles ${ }^{43}$ con la intención de que después de cada temporada de lluvias, o antes, si así se requiere, los campesinos extraigan todo lo que ahí se ha acumulado y lo viertan sobre las áreas de cultivo. ${ }^{44} \mathrm{~A}$ este sistema agrícola se le conoce como "bancal" y nos dice

40 AGN, Ordenanzas, vol. V, fs. 45-46 v.; Real acuerdo, México, agosto 30 de 1668.

${ }^{41}$ AGN, Indios, Exp. 111.

${ }^{42}$ Recopilación de leyes de los reynos de Las Indias, tomo segundo, Título 17, Ley Primera, 1550, p. 112, Mandamos a los virreyes, presidentes, gobernadores, y justicias, que den las órdenes convenientes, para que en las posadas, mesones $\mathrm{y}$ ventas, den a los caminantes bastimentos, y recaudo necesario, pagándolo por su justo precio, y que no se les hagan extorsiones, ni malos tratamientos, y todos tengan arancel de los precios justos, y acomodados al trajín, y comercio. También puede verse, como ejemplo de venta de vino, AGET, RIP, Libro 4, fs. 150-150v, 1581.

${ }^{43}$ Así se denomina a las hileras de maguey que semejan un muro.

${ }^{44}$ VERIIN, Carlos Arturo, "Sistemas y técnicas...", p. 37. 
Alba González Jácome ${ }^{45}$ que tienen básicamente dos funciones: la agrícola y la ecológica general. La primera "Permite acumulación de suelo y humedad en la parte central del piso de terrazas", mientras que la segunda "Concentra nutrientes del y en el sistema, los descompone y reduce la dependencia de ingresos externos. Permite la formación de bordos vegetales y el control de insectos. Incrementa diversidad en el sistema".

Su cultivo, al igual que en la época prehispánica, se hacía a partir de los esquejes, llamados mecuates, ${ }^{46}$ que son precisamente los "hijos" de la planta que crecen a su alrededor. Cuando éstos alcanzaban unos 80 centímetros se trasplantaban a la magueyera, tratando de que entre cada uno de ellos mediara una distancia de 3 o 4 metros para que no se obstruyeran su crecimiento. Se sembraban en hileras llamadas metepantles, metepánes o mecaleras y tenían la función de dividir los terrenos de cultivo, además de evitar, como ya lo mencionamos, la erosión de la tierra.

La vida productiva de esta planta se inicia entre los seis y doce años, se prolonga de siete a veinticinco años, dependiendo de las condiciones climatológicas, y muere poco tiempo después de haber alcanzado su madurez.$^{47}$ Esta situación es la que obligó a que se contara con plantas nuevas y de edad suficiente para que se pudieran trasplantar y reemplazar las que ya eran improductivas, sobre todo a finales del siglo xvii en que las haciendas pulqueras empezaron a comercializar el pulque en grandes cantidades.

Por otra parte, el beneficio de la grana cochinilla, que es un minúsculo insecto hemíptero ${ }^{48}$ (Coccus cacti l.) también

\footnotetext{
45 JÁCOME, Alba González, "Agroecología del suroeste de Tlaxcala", en Historia y sociedad en Tlaxcala. Memorias del 1er. Simposio Internacional de Investigaciones Socio-Históricas sobre Tlaxcala, 16 al 18 de octubre de 1985, Tlaxcala, Gobierno del Estado de Tlaxcala, Instituto Tlaxcalteca de la Cultura, Universidad Autónoma de Tlaxcala, Universidad Iberoamericana, 1986, pp. 201-220., p. 217.

${ }^{46}$ Palabra de origen náhuatl que significa "gemelos del maguey".

${ }^{47}$ PARSONS, Jeffrey y PARSONS, Mary H., Maguey utilization in highland central Mexico. An archaeological ethnography, Michigan Anthropological papers, Museum of Anthropology, University of Michigan, 1990. p. 18.

${ }^{48}$ Que cuenta con un tipo de boca que es perforadora-chupadora formada por una labio alargado que envuelve a las mandíbulas y maxilas.
} 
conocido por los españoles como cochinilla o cochinilla de grana y por los indios como nochestli (nahuas), induco (mixtecos) y bi-aa o bi-yaa (zapotecos), afectó profundamente la economía indígena, basada en el maíz, a principios del siglo xvi, debido a la rapidísima explotación que de ella se hizo.

En América se criaban dos tipos de cochinilla: la fina, que era cultivada y la silvestre. "Según parece la cultivada sólo se producía en Oaxaca, Puebla, Tlaxcala y regiones circunvecinas, mientras la silvestre se conoció en grandes regiones del Continente, y se recogía especialmente en Autlán de la Grana (Jalisco), en Chiapas y en varios lugares de Sudamérica, como Loja (Ecuador), Tucumán (Argentina) y en Brasil." 49

En la época prehispánica su cultivo era moderado y adquirió una gran demanda a partir de la segunda mitad del siglo xvi cuando los conquistadores mostraron un especial interés en este producto como materia colorante. Los españoles que acaparaban la producción exportaban grandes cantidades a Europa ${ }^{50}$ y el resto se empleaba principalmente para teñir las telas que se producían en los obrajes de Tlaxcala, Puebla, Cholula y áreas circunvecinas.

A diferencia del maguey, el cultivo de los nopales y de los pequeños insectos, requería de grandes cuidados, ya que la falta de éstos hacía peligrar las cosechas. Esta fue la principal razón por la cual los españoles no se mostraron interesados en su explotación y sólo los indios lo hicieron. Sobre el proceso de cultivo y reproducción, nos dice Dahlgren ${ }^{51}$ que:

El tinte se obtiene del cuerpo disecado de la hembra, cuyo ciclo de vida y reproducción es de tres meses. Como primer paso en el cultivo, los indios plantaban una nopalera. A los dos o tres años, cuando estaba lo bastante crecida y verde, se asemillaba, es decir, se colocaban cochinillas hembras

\footnotetext{
49 DAHLGREN, Barbro., La grana cochinilla, México: UNAM/IIA, 1990., p. 12.

50 En 1590 Bartolomé Serrano denunció la pérdida de varias arrobas de grana destinadas a Sevilla, mientras que Francisco Montero reportó haber embarcado grana para Sevilla y que por error desembarcaron en la Guaira. AGET, RIP, Libro 8, f. 154 y 155.

${ }^{51}$ DAHLGREN, La grana..., pp. 12-13.
} 
próximas a multiplicarse. Estas hembras se guardaban en las chozas, se trasplantaban de otra nopalera o, lo más frecuente, se compraban en las plazas. Para transportarlas y asemillarlas se colocaban en nidos fabricados de diversos materiales, unas quince en cada nido, que luego se ataba a las pencas del nopal o se encajaba en sus coyunturas. Al nacer los hijos se esparcen sobre las hojas hasta encontrar un lugar a propósito donde se aferran por medio de su trompa y quedan pegados alimentándose del jugo del nopal. Cuando la nueva generación salía, los indígenas bajaban a las madres, ya muertas, con pinceles suaves improvisados con pelo de cola de zorrillo u otros animales. Cuando a su vez los hijos llegaban al final de su ciclo, se bajaba toda la grana, se mataba por diferentes métodos y se ponía a secar.

Según el clima, se colocaba la semilla dos o tres veces al año; se calculaba que nacen 200 hembras por un macho y que para una libra (de colorante) se necesitan unos 70 mil insectos. ${ }^{52}$

Debido a las grandes ganancias que se obtenían por la venta de cochinilla, ${ }^{53}$ a lo largo de la segunda mitad del siglo xvi muchas familias y poblaciones enteras dejaron de cultivar los productos tradicionales y se dedicaron, casi de manera exclusiva, a cultivar la grana, lo que pronto provocó un gran desabasto de alimentos y una gran preocupación en las autoridades.

Se acusó a los indios de volverse flojos y de abandonar sus tierras de cultivo, 54 "ya que los dueños de la grana se enorgullecen con su grana; cuando es domingo y en dias festivos ya no asisten a la iglesia a escuchar misa como lo orde-

\footnotetext{
52 También es importante el escrito que sobre la grana cochinilla tiene Carlos Sempat en Tlaxcala, una historia compartida, t. 9, cap. iv, pp. 137-148 y los estudios de Silva Carlos Sánchez y Alejandro de Ávila Blomberg en la obra Memorias sobre la naturaleza, cultivo y beneficio de la grana de Joseph Antonio de Alzate y Ramirez.

${ }^{53}$ Por ejemplo, en Tlaxcala en 1587 Luis Ampuero y Alonso Herrera se comprometieron a pagar a Pedro González Delgado, 1800 pesos de oro común por 30 arrobas de grana cochinilla, o sea, $345 \mathrm{~kg}$. AGET, RIP, Libro 7, fs. 40-41v, 1587. ${ }^{54}$ Para 1590 Francisco Ximénez se obligó a pagar a Sebastián de Arriaga 600 pesos de oro común, por razón de 400 arrobas de grana sucia. Desconocemos si el primero es indio y el segundo español. 
na la santa iglesia; sólo se ocupan de que exista su alimento, su cacao; los enorgullece." 55

El prestigio que la grana tlaxcalteca obtuvo, y la demanda de este insecto fue tanta a finales del siglo xvi y principios del xvii, que en 1614 se eligió a una persona de cada una de las cuatro cabeceras para viajar a la ciudad de Campeche con la intención de "enseñar a la gente el nopal tintorero, cuando éste se pone y la manera en que se hace la tintura. En Cuetlaxcohuapa [Puebla] fueron advertidos. Los llevaron dos españoles, por orden del tlahtoani don Diego Márquez, virrey." ${ }^{\prime 6}$ Los tlaxcaltecas que viajaron fueron Gabriel Sánchez, Andrés Temizcoyoltzin, Gabriel Xico y Juan Quauhtzacualo.

En el año de 1620 se conformó el Secretario Consejo de Indias que tuvo la tarea de unificar los métodos de crianza, cosecha y beneficio de la grana en todos los centros productores de este insecto en la Nueva España. ${ }^{57}$

Lo cierto es que la cochinilla de grana, más relevante que el añil, ocupó la primacía de los colorantes. Fue producida en grandes cantidades por lo que no fue necesario crear nuevas empresas. Los métodos siguieron siendo básicamente los mismos de la época prehispánica y los españoles de la ciudad de Puebla sólo se limitaron a monopolizar su comercialización. ${ }^{58}$

\section{Agricultura europea}

Desde los inicios de la vida virreinal, la agricultura se vio enriquecida con una gran variedad de nuevas plantas. $\mathrm{Al}$ respecto "Candolla dice que de 247 plantas cultivadas en América, 199 se originaron en el Viejo Mundo, 45 en América,

\footnotetext{
${ }^{55}$ Actas de cabildo de Tlaxcala, p. 331.

56 ZAPATA Y MENDOZA, Juan Buenaventura, Historia cronológica de la noble ciudad de Tlaxcala, México: UAT/CIESAS, 1995., p. 219.

57 "Reales Cédulas, 1596-1648", pp. 481-506, en Boletín del Archivo General de la Nación, Tomo II, No. 4.

58 SEMO, Enrique, Historia del capitalismo en México. Los origenes. 1521/1763, México: Era, 1981., p. 35.
} 
y 1 en Australia...". ${ }^{59}$ Esto implicó que en muchos casos los indigenas tuvieran que aprender rápidamente a practicar un nuevo tipo de agricultura.

A pesar de que los europeos trajeron consigo importantes plantas que contribuyeron e impactaron de manera directa en la economía de las comunidades indígenas, es claro que de todas ellas la más significativa fue el trigo, del cual se cultivaba principalmente el candela y el trigo pelón, además de otras clases como el blanco, amarillo, trechel, caudeal, gordo macizo y duro.

La siembra de trigo estuvo muy extendida por todo el territorio novohispano, sin embargo existieron sitios donde se desarrollaron cultivos intensivos como fue el caso de Puebla y Tlaxcala, concretamente en las regiones de Amozoc, Tepeaca, Huamantla, Nopalucan, San Juan de los Llanos ${ }^{60}$ e Ixtacuixtla. ${ }^{61}$

Por datos dispersos en las fuentes podemos concluir que el trigo desempeñaba el papel más importante dentro de las plantas introducidas, a pesar de que su cultivo, en los siglos xvi y xvii, al parecer, se restringió sólo a las tierras comunales. "Esto se explica ya que el producto de estas tierras estaba destinado sobre todo a pagar el tributo a la Corona y el diezmo de la Iglesia. La importancia que debido a esto poseía el cultivo del trigo en los pueblos se refleja en el hecho de que era el único cultivo regado." ${ }^{2}$ Los huertos de los conventos y las hortalizas en algunos pueblos indígenas también contaron con sistema de riego.

Durante el siglo xvi parece que no existió mayor interés por parte de los españoles en cultivar el trigo, sin embargo a finales del siglo xvii y principios del xviii, los europeos se empezaron a interesar más en su siembra, no obstante muchos prefirieron adquirirlo a los indígenas y no tener que exponer sus cultivos a las inclemencias del tiempo.

\footnotetext{
${ }^{59}$ Idem, p. 33.

${ }^{60}$ Hoy Libres, Puebla.

${ }^{61}$ LIRA, Andrés y MURO, Luis, "El siglo de la integración", en Historia general de México, México: El Colegio de México, t. I, 1981, 2 v., pp. 371-470., p. 107.

62 TRAUTMANN, Wolfgang, Las transformaciones... p. 112. 
Todo parece indicar que desde el siglo xvi la siembra de trigo se hacía en surcos o montecillos y no al voleo, aunque esto no significa que esta técnica no se llegara a practicar. Por lo general la siembra estaba supeditada al sistema de temporal, sembrándose en la primavera para cosechar hacia finales del año, en noviembre o diciembre. Cuando se contaba con riego para este cultivo, hacia el siglo xvii, se sembraba en invierno y se cosechaba hacia mayo o junio. En algunos casos los indígenas sembraban trigo para venderlo a los españoles, ya que ellos no solian consumirlo. Incluso hubo quienes se aventuraron a establecer molinos y hasta hornos de pan para abastecer la demanda de los españoles.

Los frutales, que también se introdujeron en el siglo xvi, alcanzaron una rápida aceptación en las comunidades indígenas y eso favoreció su propagación.

Los indios aprovecharon los nuevos productos que trajeron los europeos y los combinaron con los que ya conocían para así fortalecer su economía familiar. Asimismo combinaron las técnicas y los sistemas agrícolas que conocían con los que trajeron los europeos. Entre estos productos conocidos por los naturales podemos mencionar los capulines (Prunuscapuli), las legumbres, las papas (Solanum tuberosum), los nopales (Opuntia spp), las peras (Pyrus communis L.), los tejocotes (Crategus mexicana), el zapote blanco (Casimiroa edulis), las manzanas (Malus sylvestris Mill.), los chayotes (Shechium edule), los membrillos (Cydonia oblonga), la alegría o amaranto (Amaranthus cruentus e hypocondriacus), ${ }^{63}$ las granadas (Punica granatum), los duraznos (Pirus comunis L.), las ciruelas (Spondias purpúrea), las nueces (Juglans regia), el tule (Stirpus lacustris), las maderas, ${ }^{64} \mathrm{y}$ las resinas, entre otros.

\footnotetext{
${ }^{63}$ ROJAS, Teresa, Las siembras de ayer, pp.184-185, nos dice que "El amaranto es uno de los granos que tienen mayor contenido nutritivo en términos químicos y orgánicos. Contiene, además de carbohidratos de alta calidad, más proteína que otros granos y cereales: de 75 a 87 en una escala de 100, en la que el maíz tiene 44, el trigo entero 56.9, el frijol soya 68 y la leche de vaca 72.2. También contiene lisina (un aminoácido esencial en el que el maíz es pobre), calcio, almidón, grasa y fibra."

${ }^{64}$ Entre éstas podemos mencionar las de pino, fresno, álamo, sabino, ailite, tepozán y encino.
} 
Es notable que la agricultura española que llegó a América no haya eliminado a la mesoamericana, sino que la integró y la revolucionó. A esta combinación de sistemas y técnicas agrícolas se le ha llamado "Agricultura Tradicional", sin embargo, como ya desde hace muchos años lo discutió Ángel Palerm, un término más adecuado para nombrar a este sincretismo agrícola sería el de Agricultura Mexicana, pues hasta la fecha se siguen practicando de manera eficaz estos procedimientos en el agro mexicano.

Con respecto a las obras hidráulicas existentes en el periodo novohispano, podemos mencionar que desde la época prehispánica se conocian muchas de ellas y que eran empleadas tanto para la agricultura como para abastecer de agua los principales centros de población. La principal fuente de abasto de agua fue, por supuesto el agua de lluvia, los manantiales, las aguas subterráneas, los pozos, las lagunas, los ríos y entre las obras existentes para la obtención del esa agua debemos destacar, los chultunes, los jagueyes, los cenotes, las presas, los diques, las redes de canales, las compuertas y los albarradones. A éstos se agregaron, durante el periodo virreinal, los acueductos en arcos, las cajas de control de flujo, las cañerías, los sifones, las estructuras de goteo, las presas, los contrafuertes, las compuertas de cabezal y las gárgolas.

De igual manera se emplearon, para elevar el agua, las norias o ruedas hidráulicas; las bombas hidráulicas; los malacates, las poleas, los rosarios y los tornillos de Arquímedes, mientras que para impulsar máquinas se utilizaron los molinos y los batanes. ${ }^{65}$

\section{Conclusión}

La agricultura fue la base de la economía de muchas poblaciones tanto en la época prehispánica como en la novohispa-

${ }^{65}$ ROJAS, Teresa. "Las obras hidráulicas mesoamericanas (Versión preliminar), XIII Economy History Congress, Session 17, (s/a), pp. 11-13. 
na. Hemos visto que muchas comunidades indigenas continuaron con sus tradicionales técnicas y sistemas agrícolas que, a pesar de que, con excepción de las chinampas, en las primeras décadas posteriores a la conquista, resolvian únicamente sus necesidades de autoconsumo, pago de tributo $\mathrm{y}$, en algunos casos, de comercio o intercambio por otros productos.

La introducción de nuevas plantas, animales, técnicas y sistemas agrícolas europeos propició que las tierras aumentaran su producción y de esta manera se incrementaron los mercados locales y regionales, a partir de una importante red de caminos que también permitió que los productos del campo llegaran a lugares cada vez más lejanos. Muchos indígenas lo aceptaron poco a poco y con el tiempo empezaron a sacar provecho de su nueva condición. Aprendieron a consumir los nuevos productos, a criar ganado e incluso se volvieron comerciantes, sacando ventaja de las necesidades de los europeos y de otras comunidades indias que se resistieron a los cambios que la conquista ofreció.

Hemos visto que la llamada Agricultura Tradicional, llamada también Agricultura Mexicana, producto del conocimiento agrícola mesoamericano y del europeo del siglo xvi, se adaptó rápidamente a las necesidades de la población novohispana y en gran medida en muchas comunidades ha continuado prácticamente igual hasta nuestro días. El estudio de la agricultura tradicional novohispana nos permite entender mucho mejor de la cultura agrícola del México actual.

\section{Agricultura tradicional en la nueva españa}

Carlos Arturo Giordano Sánchez Verín

Sintesis: La agricultura ha representado desde la época prehispánica una de las actividades más importantes en el territorio de lo que actualmente es México. Esta agricultura de origen mesoamericano, a partir de la conquista europea, se vio en la necesidad de incorporar nuevas técnicas, sistemas y, por supuesto, una gran variedad de nuevos productos como 
el trigo o la cebada. La combinación de ambas tradiciones agrícolas, la indígena y la europea, se conoce comúnmente como Agricultura Tradicional, llamada por Ángel Palerm Agricultura Mexicana, por sus características particulares.

Palabras clave: Agricultura Tradicional, Agricultura Mexicana, Nueva España, Agricultura Indígena.

Resumo: A agricultura representou desde o período preHispânico uma das atividades mais importantes no território do que hoje é o México. Esta agricultura de origem mesoamericana, a partir da conquista europeia, se achou na necessidade de incorporar técnicas novas, sistemas e, uma grande variedade de novos productos, como o trigo ou a cevada. A combinação de ambas as tradições agrícolas, a nativa e a europeia, é comumente conhecida como a agricultura tradicional, chamada por Ángel Palerm de agricultura mexicana, por suas caracteristicas particulares.

Palavras chave: Agricultura tradicional, agricultura mexicana, Nova Espanha, agricultura indigena.

Abstract: Agriculture has represented since pre-Hispanic times one of the most important activities in the territory of what is now Mexico. This Mesoamerican origin, from the European conquest onwards, was faced with the need to incorporate new techniques, systems, and, of course, a wide variety of new products such as wheat or barley. The combination of both agricultural traditions, indigenous and European, commonly known as traditional agriculture, was called by Ángel Palerm Agricultura Mexicana, by their particular characteristics.

Keywords: traditional agriculture, Mexican agriculture, New Spain, indigenous agriculture.

Recebido em 09/03/2010

Aprovado em 02/06/2010 